\title{
When technological innovations do not reach consensus: the case of tele-consultation of andrological patients
}

\author{
Paolo Verze $\mathbb{1}^{1} \cdot$ Tommaso Cai $\mathbb{1}^{2,3} \cdot$ Gianni Malossini $^{2} \cdot$ Truls E. Bjerklund Johansen $^{3,4,5} \cdot$ Raffaele Baio $^{1}$. \\ Alessandro Palmieri'
}

Received: 27 May 2020 / Accepted: 13 August 2020 / Published online: 25 August 2020

(c) Springer Nature Limited 2020

Since the end of February 2020, Italy has witnessed a complete upheaval in the organization of the national and regional health systems due to the pandemic caused by COV-SARS2 (COVID 19). An immediate consequence is a reconversion of clinical activities in all types of hospitals (public, private, and semi-private) leading to a significant delay of scheduled clinical and surgical procedures, including uro-oncological and andrological services [1,2]. Even urological emergency services have suffered from the pandemic [3].

Under normal circumstances, most clinical andrological activities are regarded as elective procedures. However, during this specific crisis, andrological services have experienced an almost total suspension of activities. As a result, the Italian Association of Andrology (SIA) promoted a series of initiatives in support of the andrological sector [4]. Uro-andrologists in SIA recognized that a period of forced home-based quarantine might exacerbate the incidence and impact of andrological diseases, especially those related to the sexual sphere. Mental health issues are frequently associated with erectile dysfunction, especially depression and anxiety-related disorders, but transitory

Paolo Verze

pverze@unisa.it

1 Department of Medicine, Surgery, Dentistry "Scuola Medica Salernitana", University of Salerno, Salerno, Italy

2 Department of Urology, Santa Chiara Regional Hospital, Trento, Italy

3 Institute of Clinical Medicine, University of Oslo, Oslo, Norway

4 Department of Urology, Oslo University Hospital, Oslo, Norway

5 Institute of Clinical Medicine, University of Aarhus, Aarhus, Denmark

6 Department of Neurosciences, Reproductive Sciences, Odontostomatology, University of Naples "Federico II", Naples, Italy states of altered mood (i.e., dysfunctional-inducing states resulting from specific life stresses) also occur [5]. Therefore, clinicians should be aware of flare-ups of andrological disorders during the COVID-19 pandemic, especially among younger patients. In some Italian regions, the local governments forced hospitals to stop physical urological and andrological outpatient visits. In this situation, SIA decided to offer patients a tele-medical specialist services as an alternative to traditional face-to-face visits. The Urology Unit of the Santa Chiara Regional Hospital in Trento followed this practice, starting from 13 March 2020. An experienced uro-andrology staff member contacted patients by phone by and offered a tele-consultation as a replacement for the scheduled physical visit.

The tele-consultations were carried out by means of a case report form made available by the hospital, which provided standardized collection of the patient's personal and clinical data and the reason for the referral. Details included actual symptoms and past and present medical history. At the end of the consultation, the physician submitted written instructions to the patient and, if required, a drug prescription through the same online platform. The following day the tele-consulted patients were contacted again by a different staff andro-urologist and were requested to answer a brief, dedicated fou-item questionnaire (4qPSQ) (Fig. 1) aimed at assessing the level of patient satisfaction with the consultation on the previous day.

Briefly, analysis of the first 57 telephone consultations in our institution showed a low rate of patients who reported the tele-consultation to be reassuring [Question 1: 30 patients (52.6\%) answered 'Neutral' and $8(14 \%)$ answered 'Disappointed'). Similarly, a low level of satisfaction with the service was reported [Question 2: 38 patients $(66.6 \%)$ answered 'Not/Somewhat'; Question 3: 35 patients (61.5\%) answered VERY POOR/POOR/NEUTRAL). Finally, only 15 patients $(26.3 \%)$ reported that they would recommend this type of service to another patient (Question 4: score $8-10)$. Table 1 contains generic patient's characteristics at 
Fig. 1 Detailed content of the patient satisfaction questionnaire. The 4-questions patient satisfaction questionnaire (4qPSQ).

The 4-questions patient satisfaction questionnaire (4qPSQ)

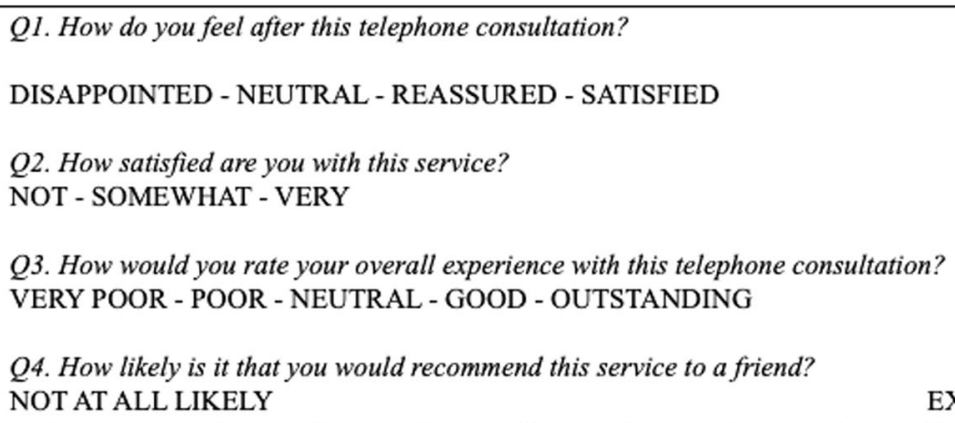


satisfactory and effective andrological consultation, which cannot be substituted by tele-medical communication. Crucial factors in the assessment such as relationship factors including partner dissatisfaction, a poor sexual relationship, intimate details, and gauging of emotions with the partner during sexual intercourse are difficult to elicit and assess during the tele-consultation process. It is obvious that all these essential emotional aspects are greatly curtailed during a tele-consultancy and hence might explain the poor satisfaction with the tele-medical approach among andrological patients. Although our small study has provided interesting findings, the importance of the results are limited by a small sample size and the use of a questionnaire that was not designed for this specific purpose and has not been validated.

\section{Compliance with ethical standards}

Conflict of interest The authors declare that they have no conflict of interest.

Publisher's note Springer Nature remains neutral with regard to jurisdictional claims in published maps and institutional affiliations.

\section{References}

1. Luciani LG, Mattevi D, Cai T, Giusti G, Proietti S, Malossini G. Tele-urology in the time of COVID-19 pandemic: here to stay? Urology. 2020. https://doi.org/10.1016/j.urology.2020.04.004.

2. Rocco B, Sighinolfi MC, Sandri M, Altieri V, Amenta M, Annino F, et al. The dramatic COVID19 outbreak in Italy is responsible of a huge drop of urological surgical activity: a multicenter observational study. BJU Int. 2020. https://doi.org/10.1111/bju.15149.

3. Porreca A, Colicchia M, D'Agostino D, Amenta M, Corsaro A, Zaramella $\mathrm{S}$, et al. Urology in the time of Coronavirus: reduced access to urgent and emergent urological care during the COVID-19 outbreak in Italy. Urol Int. 2020. 1-6. https://doi.org/10.1159/000508512.

4. Rizzo M, Liguori G, Verze P, Palumbo F, Cai T, Palmieri A. How the andrological sector suffered from the dramatic Covid 19 outbreak in Italy: supportive initiatives of the Italian Association of Andrology (SIA). Int J Impot Res. 2020. https://doi.org/10.1038/ s41443-020-0288-7.

5. Liu Q, Zhang Y, Wang J, Li S, Cheng Y, Guo J, et al. Erectile dysfunction and depression: a systematic review and meta-analysis. J Sex Med. 2018;15:1073-82.

6. Connor MJ, Winkler M, Miah S. COVID-19 pandemic-is virtual urology clinic the answer to keeping the cancer pathway moving? BJU Int. 2020 https://doi.org/10.1111/bju.15061.

7. Cai T, Verze P, Luciani L, Malossini G, Bjerklund Johansen TE, Benettollo $\mathrm{P}$, et al. What do patients say about telephone-based urological consultations at the time of the COVID-19 pandemic? Minerva Urol Nefrol. 2020 https://doi.org/10.23736/S0393-2249.20.03940-5. 